\title{
SIGS-S Mobile Saúde - A Mobile Application to Support the Collection of Health Data
}

\author{
Eduardo Fernandes \\ College of Computing \\ Federal University of Mato \\ Grosso do Sul \\ Campo Grande, Brazil \\ eduardomorfernandes \\ @gmail.com
}

\author{
Marcelo Turine \\ College of Computing \\ Federal University of Mato \\ Grosso do Sul \\ Campo Grande, Brazil \\ turine@facom.ufms.br
}

\author{
Maria Istela Cagnin ${ }^{*}$ \\ College of Computing \\ Federal University of Mato \\ Grosso do Sul \\ Campo Grande, Brazil \\ istela@facom.ufms.br
}

\begin{abstract}
The Brazilian government has asked for information systems to support government activities such as health care. Aiming to support the collection of health data in the context of the Health in The Family Program (Programa Saúde na Família) promoted by the Single Health System of Mato Grosso do Sul (Sistema Único de Saúde do Estado de Mato Grosso do Sul - SUS-MS), it was developed the mobile application SIGS-S Mobile Saúde. The purpose of the mobile application is to provide the collection of health data in places where there is no internet connection using mobile devices such as tablets, providing the collected data to a web system called SIGS-S Web Saúde via internet data transfer. A software process, named ProFap, was used to support the mobile application development. As a result, the mobile application was developed and its documentation was prepared to help future software maintenance and the deployment of SIGS-S Mobile Saúde in the context of health care by SUS-MS. The application was developed and validated with participation of stakeholders consisting of health users and Brazilian government managers.
\end{abstract}

\section{Categories and Subject Descriptors}

H.4.m [INFORMATION SYSTEMS APPLICATIONS]: Miscellaneous; K.6.1 [MANAGEMENT OF COMPUTING AND INFORMATION SYSTEMS]: Project and People Management - Systems analysis and design; K.6.3 [MANAGEMENT OF COMPUTING AND INFORMATION SYSTEMS]: Software Management - Software Development, Software Process

\footnotetext{
*Financial support from Fundação de Apoio ao Desenvolvimento do Ensino, Ciência e Tecnologia do Estado de Mato Grosso do Sul (FUNDECT) - T.O. n. 0072/12.
}

Permission to make digital or hard copies of all or part of this work for personal or classroom use is granted without fee provided that copies are not made or distributed for profit or commercial advantage and that copies bear this notice and the full citation on the first page. To copy otherwise, to republish, to post on servers or to redistribute to lists, requires prior specific permission and/or a fee.

SBSI 2015, May 26th-29th, 2015, Goiânia, Goiás, Brazil

Copyright SBC 2015.

\section{General Terms}

Development, Design, Documentation

\section{Keywords}

Information systems, health care, mobile application

\section{INTRODUCTION}

The Brazilian government has asked for information systems in order to support government activities from different areas, such as health care. e-SUS - Primary Care ${ }^{1}[1]$, used by the Single Health System (Sistema Único de Saúde - SUS) on a national scale, is an example of information system whose goal is to provide health care management.

Other government information system for health care management is SIGS-S Web Saúde [9], a web system that crosses social and health data to provide management reports for support decision-making to both areas. It was conceived to be used by Single Health System of Mato Grosso do Sul (Sistema Único de Saúde do Estado de Mato Grosso do Sul SUS-MS).

Aiming to support the collection of health data to be sent to SIGS-S Web Saúde, it was proposed the mobile application SIGS-S Mobile Saúde. Its purpose is to provide data collection remotely, in places where there is no internet connection - therefore, there is no access to the web system - through the use of mobile devices. This application was also conceived to send the collected data from SIGS-S Mobile Saúde to SIGS-S Web Saúde via internet.

SIGS-S Mobile Saúde was developed in the context of a research project of the Laboratory of Software Engineering (Laboratório de Engenharia de Software - LEDES) at the Federal University of Mato Grosso do Sul (UFMS) [4]. The application is part of a set of applications to support social and health data management called SIGS-S.

The development of SIGS-S Mobile Saúde was supported by the ProFap software process [5], and it was accompanied and validated by health users and Brazilian government managers.

As a result, it was developed the mobile application SIGSS Mobile Saúde and prepared its documentation to support future maintenance and the application deployment in the context of the Health in The Family Program of SUS-MS.

\footnotetext{
${ }^{1}$ cited in this paper only by e-SUS.
} 
The remainder of this paper is organized as follows. In Section 2, the SIGS-S project is described. In Section 3, the ProFap process is presented. In Section 4, related works are discussed. In Section 5, we present details about the development of the SIGS-S Mobile Saúde. Finally, in Section 6 , the conclusions and future work are presented.

\section{THE SIGS-S PROJECT}

The Information System on Social and Health Management (Sistema de Informação em Gestão Social e da Saúde - SIGS-S) is a research project developed in LEDES by a development team that consisted of undergraduate students in Computer Science and Systems Analysis, teachers from UFMS and health professionals from SUS-MS [4].

The project consists of a web system called SIGS-S Web [9], for social and health data management, and a mobile application called SIGS-S Mobile Saúde [7], for support the collection of health data to be sent to SIGS-S Web via internet.

The SIGS-S project was completed in December 2014. It will be sent, in the first half of 2015, to the Information Technology sector of SUS-MS in order to be analyzed and perhaps deployed in the Health in The Family Program scope.

\subsection{SIGS-S Web}

SIGS-S Web is a web system that integrates social and health subsystems to provide management reports by crossing data from both subsystems [9]. To meet this goal, SIGS$\mathrm{S}$ Web was implemented in modules. Each module represents an specific feature of the web system, and there are access permissions for each module in order to make them private or shared between subsystems. The two SIGS-S Web subsystems have different goals but are unified by a single user interface. The subsystems are:

- SIGS-S Web Social: this is a web system to support social data collection for management of social programs offered by the Brazilian government; and

- SIGS-S Web Saúde: this is a web system to support health data collection, based in e-SUS forms, for generation of management reports to SUS-MS. An advantage when compared to e-SUS, SIGS-S Web Saúde provides integration with SIGS-S Mobile Saúde, presented in this paper.

The web system was implemented using open source or freeware tools, such as: Bizagi Modeler for BPMN diagrams, brModelo for logical models, PostgreSQL 9.1 with pgAdminIII, XML 2.0, HTML 5.0 and PHP 5.4 [9].

SIGS-S Web is based on the Titan Framework [6], that is framework for web systems development implemented in PHP and XML. This framework belongs to the e-government domain and uses the Model-View-Controller (MVC) pattern [8].

\subsection{SIGS-S Mobile Saúde}

SIGS-S Mobile Saúde [7] was conceived to support the remote collection of health data to be sent to SIGS-S Web Saúde. Its purpose is to provide a way of health professionals to fill forms remotely, in places where there is no internet connection, through mobile devices with the application installed. After the collection, the collected data can be exported to SIGS-S Web via internet, through web services.
The mobile application was conceived to provide the following features:

- Metadata and professional data import: metadata from SIGS-S Web Saúde are imported to SIGS-S mobile Saúde to be used for completing health forms;

- Health forms: the purpose is to provide the same health forms available in SIGS-S Web Saúde, to be filled and stored on the mobile device; and

- Forms export: the purpose is that the filled forms can be exported, via internet, from SIGS-S Mobile Saúde to SIGS-S Web Saúde. The communication between platforms is provided by web services.

The main feature of SIGS-S Mobile Saúde is the form filling to support the collecting of data to be sent to SIGS-S Web Saúde. This feature consists of a similar implementation of the health forms provided by the web application, in order to make the usage easier. Consequently, the implementation of the mobile application forms is based on the forms available by e-SUS web system.

The ten health forms provided by SIGS-S Web Saúde were implemented in SIGS-S Mobile Saúde, which are [7]:

- Individual Care: form for individual care, including data related to health conditions, ordered and attended examination;

- Odontologic Individual Care: form for odontologic individual care, including types of medical consultation and dental procedures;

- Collective Activity: form for collective activity register. This form consists of two sub-forms: Collective Activity, for register of collective activities with participation of assisted people, and Collective Activity/Meeting, only for meeting among health professionals;

- Household Registration: for household registration, including data about housing conditions and each responsible for families inhabitants of the home;

- Individual Registration: for individual registration. This form consists of two sub-forms: Individual Registration, for registration of domiciled individual only, and Individual Registration/Homeless: for registration of homeless people only;

- Procedures: form for procedure and small surgeries registration. This form consists of two sub-forms: Procedures, for procedure and small surgeries registration only, and Procedures/Consolidated Procedures, for consolidated procedure (generic medical procedure) registration; and

- Home Visit: form for home visit registration, for accompanying of assisted people.

The main innovation factors of SIGS-S Mobile Saúde are:

- The mobile application provides integration between social and health data; 
- It is integrated with a web system that meets the latest needs of the health primary care of the Brazilian government;

- It aimed to meet a demand of primary care office for mobility in health care by providing the main features required for remote health data collection; and

- It was developed with regular monitoring of primary care staff, who provided suggestions for features and functionality commonly required by the primary care team. This factor directed the application development to the real needs of future users.

\section{PROFAP}

ProFap [5] consists of a collaborative software maintenance process that is integrated with some support tools, such as the system for project management and reporting bugs Redmine ${ }^{2}$; and the software versioning and revision control system Subversion $(\mathrm{SVN})^{3}$. It is used for software maintenance and also for software development in various project developed in LEDES. ProFap was also used in the development of SIGS-S Mobile Saúde. The stages of ProFap, and their flow, are illustrated in Figure 1.

The request of maintenance and the report of bugs are made via Redmine in stage Request Maintenance. Requests related to corrective maintenance are assigned to developers, and requests related to new modules or functionality to be implemented are submitted to analysis by committee consisting of stakeholders.

Next, the viability and need of a request is evaluated in stage Approve Maintenance Request. Here, a request can be approved or discarded. In stage Design Solution is where an approved request is assigned to a developer, and where developers with related tasks discuss ways of designing solutions for their tasks, with accompanying of team leaders.

In stage Implement Solution and Conduct Unit Tests the solution is implemented with support of the SVN versioning. This is also where the functional and unit tests are conducted by the developer in local environment. This stage is parallel to the stage Design Solution.

The stage Conduct Integration and Acceptance Tests is where the test environment is updated with support of SVN and Redmine. This is also where the integration tests are conducted in test environment. During the acceptance tests, the developer is able to request support from other developers, but the acceptance tests are always made by the client. Lastly, in stage Finally Maintenance Task the request is closed, via Redmine. This is also where the production environment is updated with the new implementation using SVN.

\section{RELATED WORK}

The Brazilian government has invested in some mobile applications to support health care, such as disease treatments and treatment request. Through a not systematic research made in this scope, a few amount of mobile applications were found.

\footnotetext{
${ }^{2}$ http://www.redmine.org/

${ }^{3}$ https://subversion.apache.org/
}

As an example, there is the UNA-SUS Dengue [12], released by the Open University of SUS (Universidade Aberta do SUS - UNA-SUS) in December 2012. This application was developed by an UNA-SUS team of the Federal University of Health Sciences of Porto Alegre (Universidade Federal de Ciências da Saúde de Porto Alegre - UFCSPA), and it was designed to aid in the diagnosis and treatment of dengue.

Other example of government mobile application for health support is the e-SUS SAMU [11]. This is an application released by the Ministry of Health in January 2014 to provide service requests for the Emergency Mobile Service (Serviço de Atendimento Movél de Urgência - SAMU) via mobile devices.

Another example of mobile application whose goal is to support data health, specifically in the context of health care, is the GeoHealth, an application developed by the West Region Project (Projeto Região Oeste) of the School of Medicine of the University of São Paulo (FMUSP) [10]. GeoHealth consists of a mobile application to support data collection to the primary health care. The collected data is sent to the Information System of Primary Care (Sistema de Informação da Atenção Básica - SIAB), that is a system being replaced by e-SUS.

At last, the e-SUS Home Care (e-SUS Atenção Domiciliar - e-SUS AD) is a mobile application for health data collection [2]. e-SUS AD provides citizen registration and health care records. It is also integrated to a desktop application called Citizen Electronic Medical Record (Prontuário Eletrônico do Cidadão - PEC), for data exchange. However, the application is oriented to home care only.

Considering that the data collection is an important step to the management of health care, because it is where health professionals interacts with the assisted people, the proposal of an application that facilitates the process is something quite interesting. However, there is still no mobile application to support the collection of health data to be sent to the current information system used by SUS, the e-SUS Primary Care.

In particular, there is still no application oriented to support the collection of data for the health primary care of the Brazilian government following the parameters of the National Plan for Primary Care (Plano Nacional de Atenção Básica - PNAB) [3].

\section{DEVELOPMENT OF SIGS-S MOBILE SAÚDE}

This section presents the development of SIGS-S Mobile Saúde, including the main design decisions, the adopted technologies, the use of ProFap in the development of the mobile application, its architecture and graphic user interface.

\subsection{Design of SIGS-S Mobile Saúde}

The mobile application was implemented to be used as follows [7]:

1. In the first use of SIGS-S Mobile Saúde, an user registers a mobile device in SIGS-S Web Saúde to be able to install the mobile application;

2. The user installs the mobile applications SIGS-S Mobile Saúde and Barcode Scanner (a freeware application for QR code reading) on the registered device; 


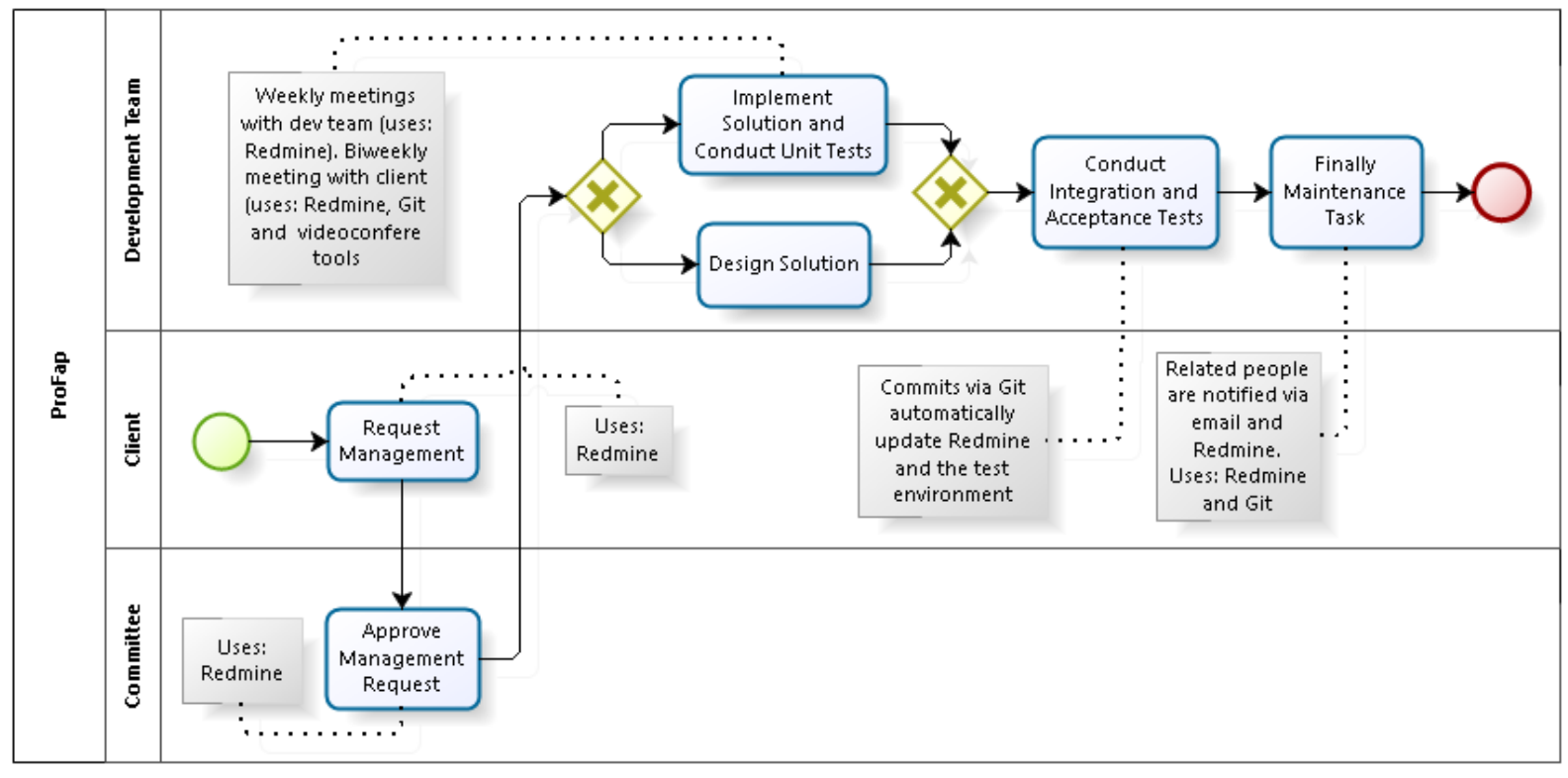

Figure 1: Stages of ProFap [5].

3. The user performs the first access to the mobile application SIGS-S Mobile Saúde. When the application starts, it is automatically redirected to Barcode Scanner for device registration using QR code. Then, the mobile device is associated to SIGS-S Web Saúde and authorized to use the mobile application;

4. The user performs authentication in SIGS-S Mobile Saúde as illustrated in Figure 2. Therefore, it is necessary that the user is properly registered in the web system. This is the start point for accesses after the device registration;

5. After authenticated, the user can access SIGS-S Mobile Saúde and its resources. In a first moment, the user must to request data (metadata and health professional data) import to complete forms. The import procedure is detailed in Figure 3;

6. The user is able to fill the health forms that are available by the application;

7. After the forms filling, the user must to export the collected data, from SIGS-S Mobile Saúde to SIGS-S Web, via internet connection. After the export, the exported data is deleted of the mobile database. The export procedure is illustrated in Figure 4.

Basically, during the user authentication procedure, the user informs login and password that are verified in the mobile database. If the user credentials matches with any user locally saved, then the user is authenticated. Else, the application needs internet connection to search for the informed user via web service. In this case, if the user is found in the web database, then the user data is retrieved from the web database and sent to the mobile database, via web service, in a JSON formatted file, and the user is authenticated. Otherwise, the user authentication is not confirmed.

During the import data procedure, the mobile application generates a JSON formatted file with parameters to support the data search. This file is sent to the web service, that retrieves the data of interest from SIGS-S Web Saúde database and record the data in a JSON formatted file. Then, the recorded file is sent, via web service, to SIGS$\mathrm{S}$ Mobile Saúde that validates the retrieved data and performs data persistence.

During the export data procedure, the health forms persisted in the mobile database are recorded in a JSON formatted file that is sent to the web service. The web service validates the format of the received file and persists the data in the web database. Then, the web service sends a success or error message to the mobile application.

The minimum requirements defined for an satisfactory use of SIGS-S Mobile Saúde in mobile devices, aiming to avoid problem of execution and slowness, are [7]: Android operating system in the version 3.0 or greater, display size greater than or equal to seven inches, $500 \mathrm{MB}$ storage, 1 GB RAM and wireless connectivity.

The technologies chosen to develop SIGS-S Mobile Saúde are listed in Table 1.

\subsection{Use of ProFap in the Development of SIGS- S Mobile Saúde}

SIGS-S Mobile Saúde was developed with support of ProFap [7].

The meetings of the development team with the stakeholders were made in the stage Request Maintenance, in order to discuss the features that should be implemented in the application. Some meetings were in person, other were conducted via email.

The weekly meetings of the development team were conducted according to the stage Approve Maintenance Request, in order to discuss the viability of each application feature proposed in the stage Request Maintenance.

The implementation of the application features were made in the stage Implement Solution and Conduct Unit Tests by the development team. The team also conducted unit tests in this stage. In parallel, according to the stage Design 


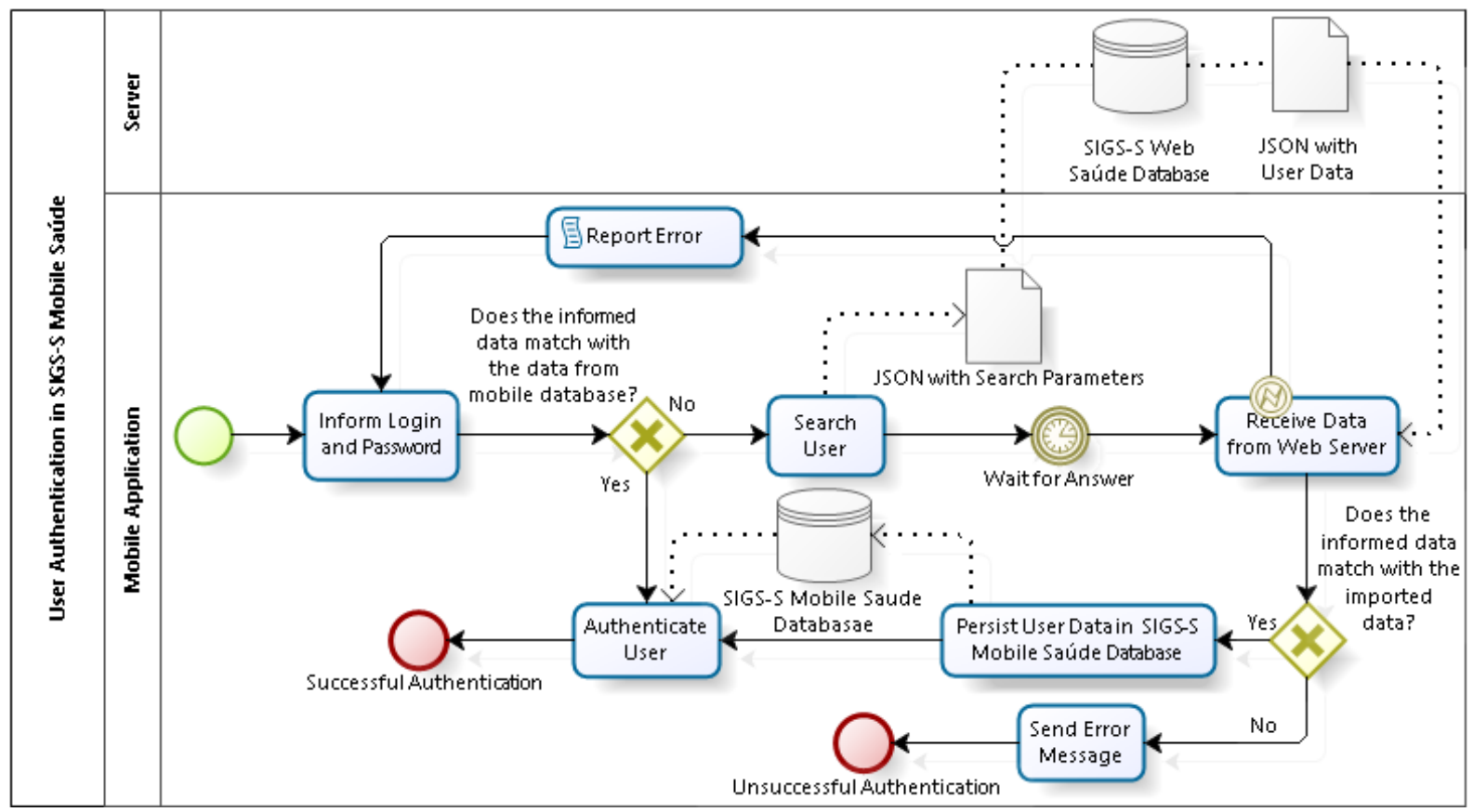

Figure 2: User Authentication Steps [7].

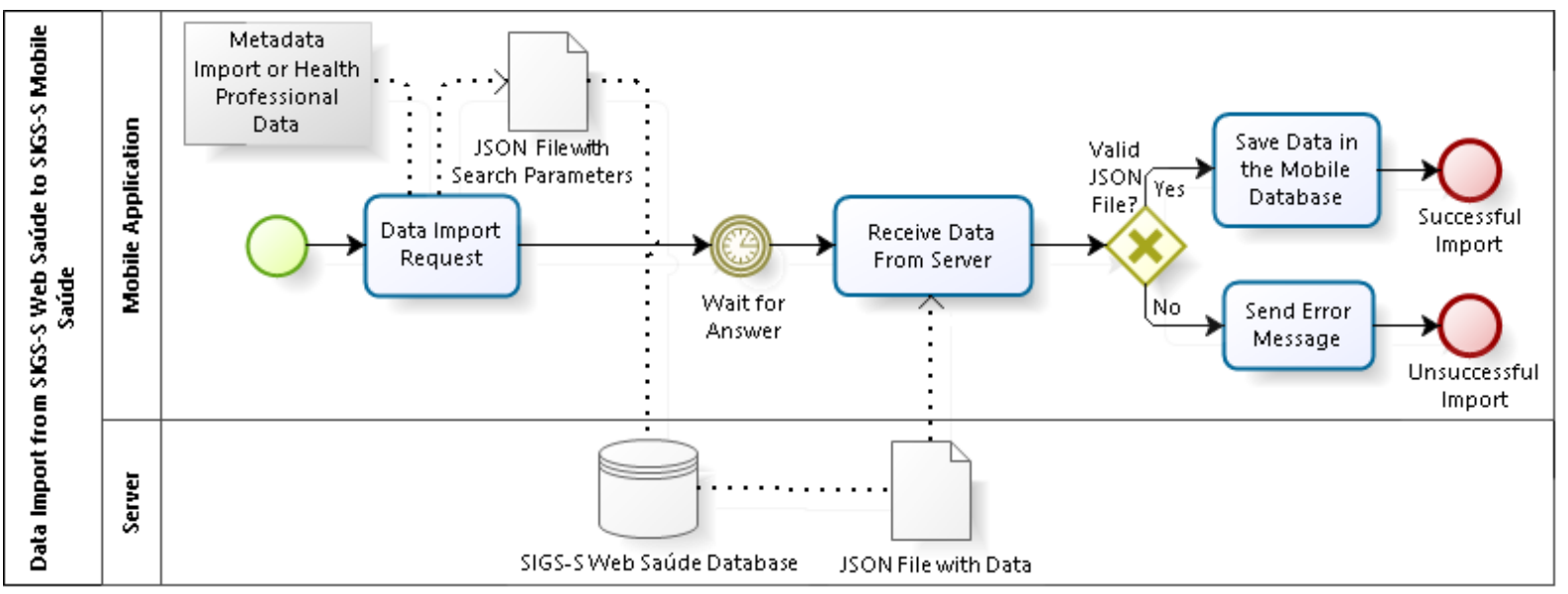

Figure 3: Import Data Steps [7].

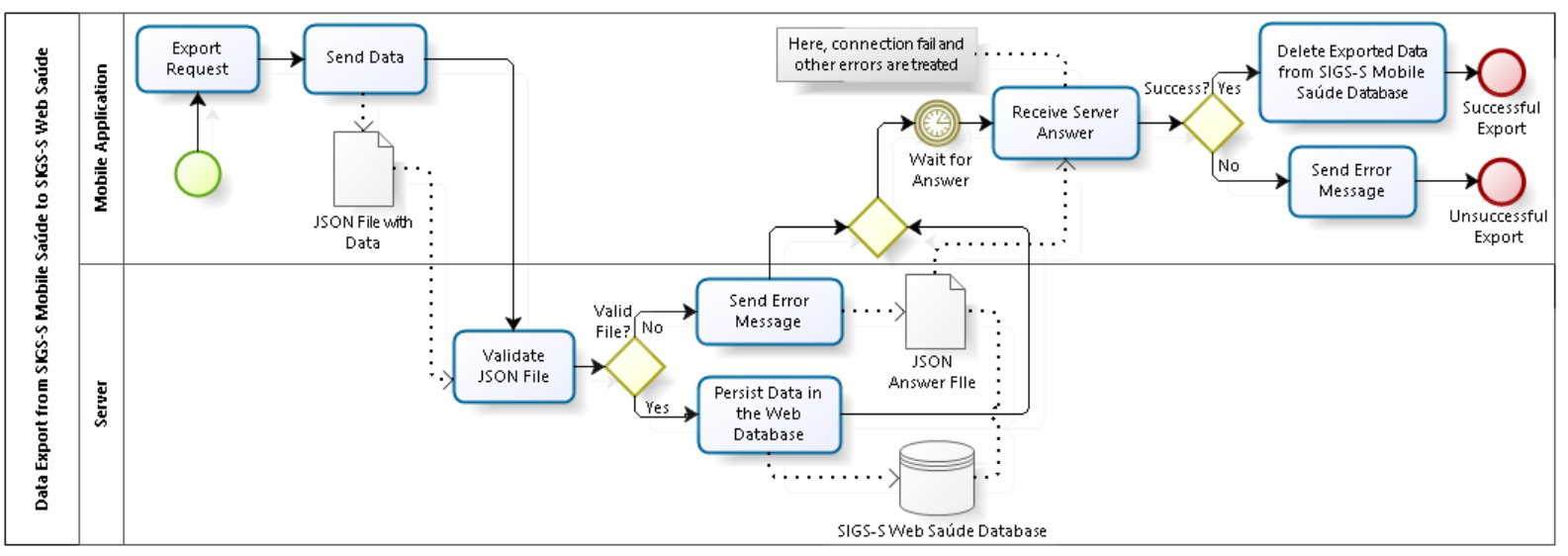

Figure 4: Export Data Steps [7]. 
Table 1: Technologies used to develop SIGS-S Mobile Saúde [7].

\begin{tabular}{|l|c|}
\hline Purpose for Mobile & Tool \\
\hline $\begin{array}{l}\text { Software Library flite } \\
\text { Databases }\end{array}$ & Fluid UI \\
\hline Mockup Tool & JSON \\
\hline $\begin{array}{l}\text { Standard Format for Data Transmis- } \\
\text { sion }\end{array}$ & Eclipse ADT \\
\hline $\begin{array}{l}\text { Integrated Development Environ- } \\
\text { ment for Android Development }\end{array}$ & Levels 14 to 19 \\
\hline $\begin{array}{l}\text { Application Programming Interface } \\
\text { for Android Platform }\end{array}$ & pgAdminIII \\
\hline $\begin{array}{l}\text { Graphic User Interface for Database } \\
\text { Management Systems }\end{array}$ & Java 2.0 \\
\hline Markup Language & OrmLite \\
\hline $\begin{array}{l}\text { Programming Language for Android } \\
\text { Applications }\end{array}$ & PHP 5.4 \\
\hline $\begin{array}{l}\text { Package for Object-Relational Map- } \\
\text { ping and Mobile Data Persistence }\end{array}$ & SVN Workbench \\
\hline $\begin{array}{l}\text { Graphical Client for Subversion } \\
\text { vice Implementation }\end{array}$ & PHer Web Ser- \\
\hline
\end{tabular}

Solution, the development team discussed the best ways to implement each assigned task. All the design decisions were properly documented and included in the technical manual of SIGS-S Mobile Saúde.

The integration tests were conducted according to the stage Conduct Integration and Acceptance Tests, by the development team. Furthermore, the acceptance tests were conducted by the team together with stakeholders. In addition, meetings were held in order to present and validate the implementation results with the stakeholders.

At last, the implemented source code was versioned via SVN according to the stage Finally Maintenance Task.

In addition to the documents related to meeting, the development team developed the following artifacts [7]:

- Requirements Document: this document describes the main features of the mobile application, including functional and non-functional features such as data security and the minimum requirements;

- BPMN diagrams: it was developed a set of BPMN diagrams to illustrate the flow of key features of the application, such as user authentication, data import and data export:

- Technical manual: is describes the design decisions in order to support future software maintenance;

- User manual: this document was developed to support the application deployment in the context of the Health in The Family Program; and

- Other documents: during the development of SIGS-S Mobile Saúde, it was developed a set of documents to help in the development process, such as spreadsheets and text files describing design decisions, development parameters, adopted patterns and assigned tasks.

\subsection{SIGS-S Mobile Saúde Development Steps}

The steps of development of SIGS-S Mobile Saúde were:
- User interface implementation: this step consisted of the user interface implementation aiming to design the visual layer of the application based on e-SUS forms;

- Database implementation: this step consisted of the database implementation (database classes and data persistence). The tables were prioritized as follows: first the metadata tables, after the other tables;

- Data import implementation: this step consisted of the implementation of data import scripts (to transfer data from SIGS-S Web to SIGS-S Mobile Saúde). Furthermore, it was implemented features to support data import in the mobile application;

- Professional data import implementation: in this step, it was considered the implementation of professional data import feature and other features to support the data import;

- Export data implementation: this step consisted of the export feature implementation, in addition to web services to provide the exportation from SIGS-S Mobile Saúde to SIGS-S Web.

As mentioned above, the development did not consisted only of the SIGS-S Mobile Saúde implementation, but also of the web service implementation. The web services were conceived to provide communication between the mobile application and SIGS-S Web Saúde, in order to enable data import and export [7].

The web service scripts were implemented in PHP language and the JSON format was adopted in the data transfer. The software architecture style used in the development of the web services was the Representational State Transfer (REST). Furthermore, no security solution has been implemented beyond that provided by the HTTP protocol adopted to data transfer.

\subsection{Architecture of SIGS-S Mobile Saúde}

The architecture of SIGS-S Mobile Saúde is illustrated in Figure 5 and was based in Android application patterns.

Basically, the architecture of the mobile application consists of the following layers:

- User interface layer: it is responsible for user interaction with the application;

- Controller layer: it is responsible for interface control as the user interacts with the application;

- Business layer: it consists of the entities that can be persisted on the database;

- Persistence layer: it is responsible for the database persistence implemented with support of OrmLite;

- Infrastructure layer: it consists of the web service scripts that provide communication between SIGS-S Web Saúde and SIGS-S Mobile Saúde. It consists also of the mobile database.

\subsection{User Interface of SIGS-S Mobile Saúde}

The user interface of SIGS-S Mobile Saúde, illustrated in Figure 6, was designed to be similar to the interface of SIGS$\mathrm{S}$ Web Saúde, in order to help the user in adapting to the use of the mobile application. Furthermore, it was developed following the visual patterns of the forms available by e-SUS, to make easier the usage learning of the application. 


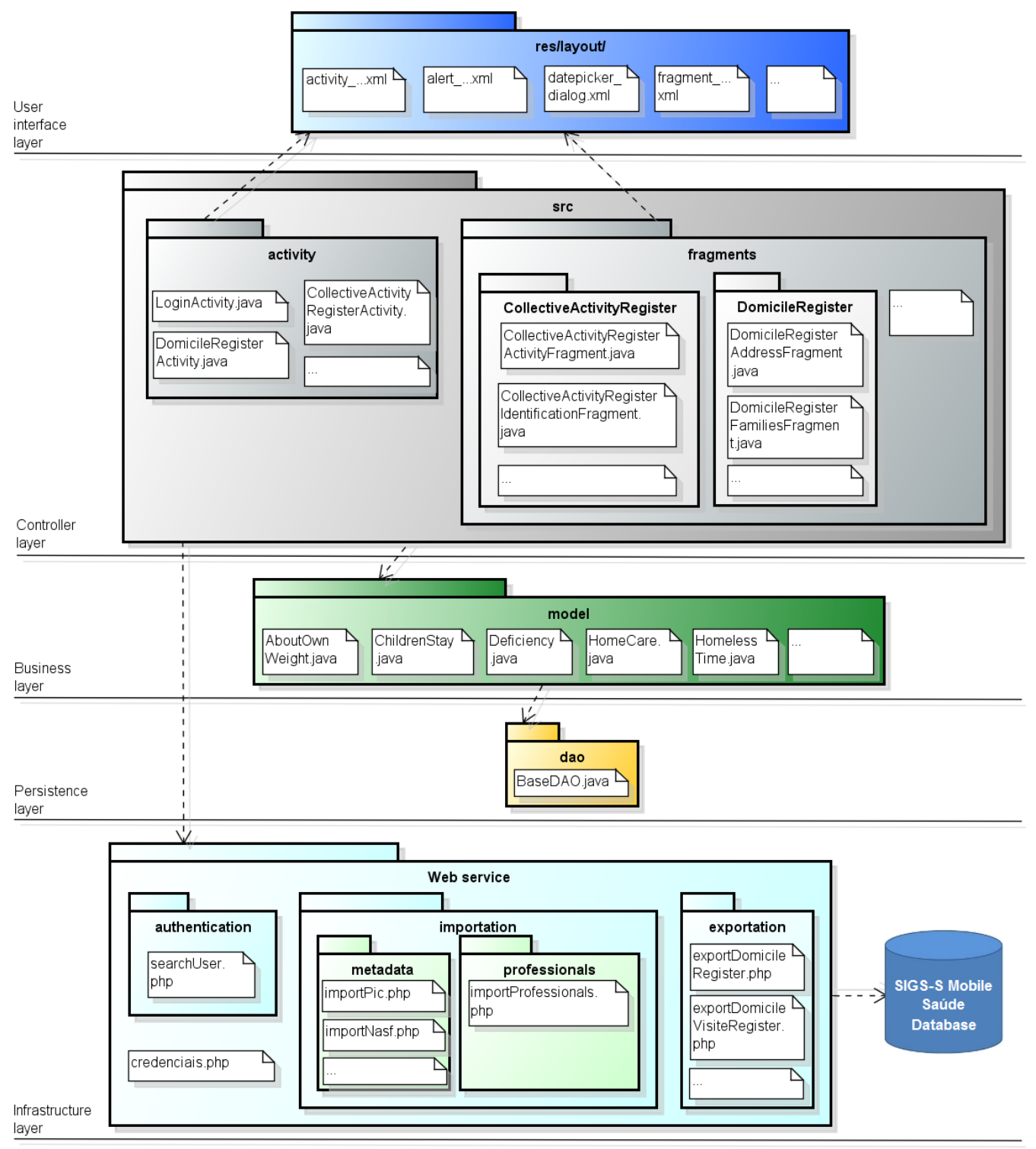

Figure 5: Architecture of SIGS-S Mobile Saúde.

\section{CONCLUSIONS}

The main contributions of this work is the development of SIGS-S Mobile Saúde, a mobile application to support SIGS$\mathrm{S}$ Web Saúde providing remote data collection in places where there is no internet connection. Stakeholders (health users and Brazilian government managers) participated during development and validation of the application.

The development of SIGS-S Mobile Saúde has been facilitated by ProFap, which encourages the user participation during software development and the usage of CASE tools, that sped up the development team work.

Among the difficulties and challenges faced during development, are: delays in the development of SIGS-S Web Saúde, that delayed the development of the mobile application mainly due to design decisions that should be taken together with the web development team; the learning new technologies as the Android platform; and the use of ProFap and support tools in the development of mobile applications.

This study has some limitations: the mobile application was not implemented with all the features of SIGS-S Web, such as user management; it was not considered, in both applications, other usage scenarios than the most common; and the application has not been evaluated with real users.

Some suggestions for further work are: the conduction of acceptance tests with health user; the deployment of the mobile application in the context of Health in The Family Program by SUS-MS; and increase SIGS-S Mobile Saúde to cover other usage scenarios than the most common, aiming to meet other recurrent situations of the health care.

\section{ACKNOWLEDGMENTS}

This research was supported by Fundação de Apoio ao Desenvolvimento do Ensino, Ciência e Tecnologia do Estado de Mato Grosso do Sul (FUNDECT). The authors would like 


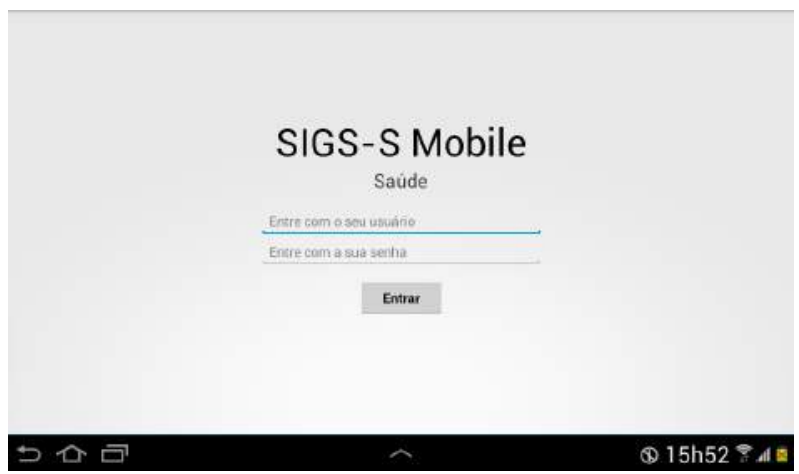

(a) Welcome screen, for user authentication.

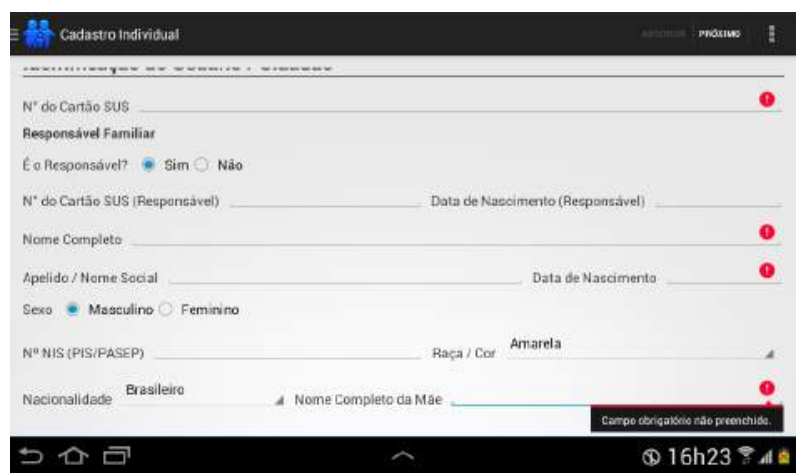

(b) Example of health form with field validation.

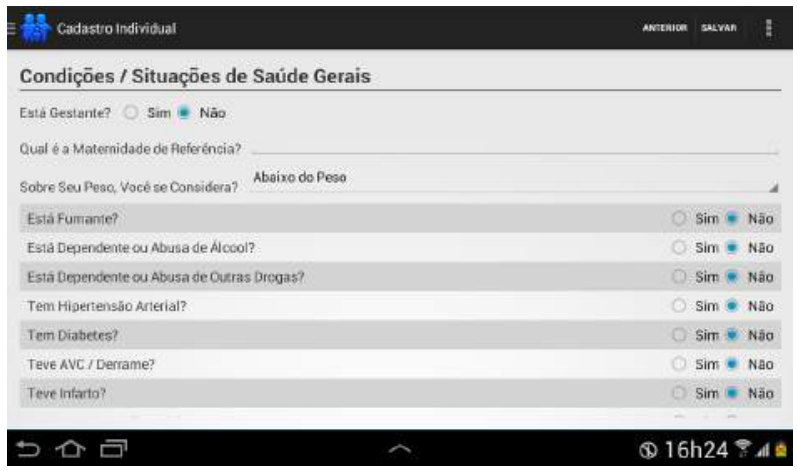

(c) Other example of form screen.

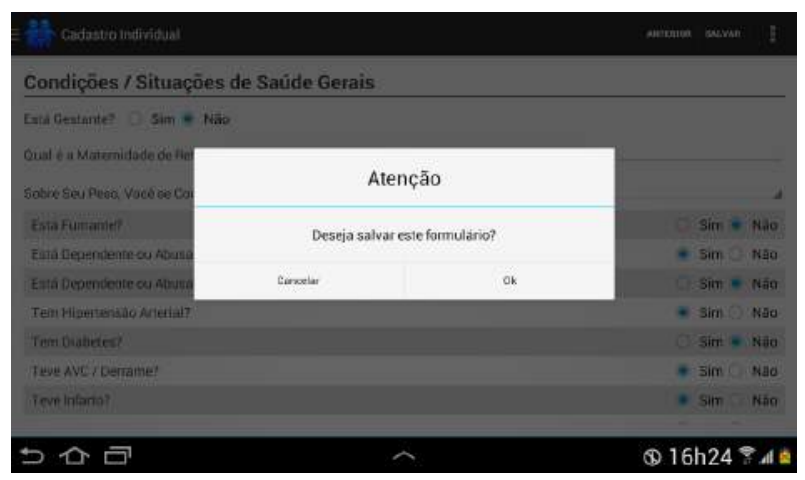

(d) Example of form recording message.

Figure 6: User interface of SIGS-S Mobile Saúde. to thank Douglas de Souza and Eliton Perin from mobile development team, and MSc. Márcio Aparecido da Silva.

\section{REFERENCES}

[1] Brazil. e-SUS Primary Care. Portal da Saúde. Available at: http://dab.saude.gov.br/portaldab/ esus.php (in portuguese).

[2] Brazil. e-SUS Primary Care. Guia para instalação e utilização do prontuário eletrônico do cidadão na Atenção Domiciliar (módulo e-SUS AD). 2014. Available at: http://189.28.128.100/dab/docs/ portaldab/documentos/guia_ad_v_1_3.pdf. (in portuguese).

[3] Brazil. Health Ministry. Primary Care National Policy. Brasília: Health Ministry (Health Legislation Series). 2012. Available at: http://dab.saude.gov.br/ portaldab/pnab.php (in portuguese).

[4] M. Cagnin, A. Acosta, C. Gonçalves, C. Vieira, D. Blanes, E. Smaka, H. Sandim, J. Luna, K. Costa, M. Alvarenga, M. Silva, and M. Oliveira. Information Management of Benefited Families in the Family Health Program in the Campo Grande-MS City. Research project approved in FUNDECT/DECIT-MS $/ \mathrm{CNPq} / \mathrm{SES}$ N. 04/2012. 2012. (in portuguese).

[5] M. Cagnin, M. Turine, M. Silva, G. Landre, L. Oliveira, V. Lima, M. Santos, D. Paiva, and C. Carromeu. ProFap: Collaborative Process of Software Maintenance. X Workshop de Manutenção de Software Moderna, Distrito Federal, Brasil, 2013.

[6] C. Carromeu, D. Paiva, M. Cagnin, H. Rubinsztejn, M. Turine, and K. Breitman. Component-Based Architecture for e-Gov Web Systems Development. 17th IEEE International Conference and Workshops on Engineering of Computer-Based Systems, Oxford, UK, 2010.

[7] E. Fernandes, D. Souza, and M. Cagnin. SIGS-S Mobile Saúde: A Mobile Application to Support the Health Data Collection. 2014. Monograph, Bachelors Degree in Computer Science, College of Computing, UFMS. (in portuguese).

[8] M. Fowler, E. Hieatt, R. Mee, and R. Stafford. Patterns of Enterprise Application Architecture. 2003.

[9] I. Ortiz, N. Borine, Y. Brito, and M. Cagnin. SIGS-S Web: A Web Application to Support the Social and Health Management. 2014. Monograph, Bachelors Degree in Systems Analysis, College of Computing, UFMS. (in portuguese).

[10] M. Pivetta. Paciente na ponta da linha. Pesquisa FAPESP, (172):39, 2010. Available at: http://revistapesquisa.fapesp.br/wp-content/ uploads/2012/07/038-039-172.pdf?caf4da. (in portuguese).

[11] Portal Brasil. Saúde lança aplicativo que integra SAMU 192 ao Facebook. 2014. Available at: http://www.brasil.gov.br/saude/2014/01/saudelanca-aplicativo-que-integra-samu-192-aofacebook. (in portuguese).

[12] UNA-SUS. Aplicativo para celular auxilia no diagnóstico da dengue. 2013. Available at: http://www . unasus .gov . br/noticia/aplicativopara-celular-auxilia-no-diagnostico-da-dengue. (in portuguese). 